\title{
EL CANSANCIO ANTROPOLÓGICO EN EL IMAGINARIO ACTUAL Y LA TRANSMISIÓN DE LA FE ANÁLISIS FILOSÓFICO Y TEOLÓGICO
}

\author{
SANTIAGO GARCÍA MOURELO \\ Universidad Pontificia Comillas, Madrid
}

\begin{abstract}
RESUMEN: El este ensayo, describe uno de los elementos del imaginario contemporáneo: el cansancio antropológico, según los análisis del filósofo y sociólogo Byung-Chul Han y convergente con las aportaciones del antropólogo David Le Breton. Desde este trasfondo cultural y antropológico, y con el ánimo de liberar de sus consecuencias, el logos de la fe propone la educación del deseo y la esperanza, con el fin de ampliar el horizonte de compresión de lo humano y ofrecer vías de solución.

PALABRAS CLAVE: Byung-Chul Han; antropología; imaginario antropológico; sociedad del cansancio; transmisión de la fe; deseo; esperanza.
\end{abstract}

\section{The anthropological tiredness in the current imaginary and the transmis- sion of faith. Philosophical and theological analysis}

ABSTRACT: This essay describes one element of the contemporary imaginary: anthropological fatigue, according to the analyzes of the philosopher and sociologist Byung-Chul Han and converging with the contributions of the anthropologist David Le Breton. From this cultural and anthropological background, and with the aim of freeing it from its consequences, the logos of faith propose the education of desire and hope, in order to broaden the horizon of understanding of the human and offer ways of solving it. KEY WORDS: Byung-Chul Han; anthropology; anthropological imaginary; society of fatigue;transmission of faith; desire; hope.

Abordar la cuestión del imaginario del hombre contemporáneo se plantea como una empresa difícil y arriesgada. Difícil por la complejidad socio-cultural que habitamos y arriesgada porque el imaginario, no es algo que salte a la vista. Por ello, se hace necesaria una actitud fenomenológica y hermenéutica que sepa dar cuenta del conjunto de ideas, valores y referencias, que laten tras las concreciones culturales. Como recordó, el siempre inspirador, A. Gesché:

«La teología tiene su manera propia de estar al servicio de la fe, de estar a la escucha, en cada instante y a cada momento de la historia humana, de los retos y los interrogantes de esta historia. “¿Qué es lo que cuentan los hombres?". Una teología que no acompañara, para escuchar y comprender, y también para discernir, estos movimientos del espíritu, no prestaría el servicio que se espera de ella» ${ }^{1}$.

A su vez, una vez escuchado el mundo, el logos de la fe deberá sopesar qué palabras de su vasto acervo, puedan ser las acertadas para que el mundo reciba como buena noticia aquello que lo motiva, sostiene y orienta. No sea que, poseyendo lo mejor, no sepamos mostrarlo de manera inteligente y creíble.

A. Gesché, La teología, Sígueme, Salamanca 2017, 29. 
En esta búsqueda del imaginario contemporáneo, la perspectiva teológica tiene como prioridad y tarea fundamental interpretar lo que la fe nos dice sobre Dios y sobre el hombre. Una hermenéutica prudente y humilde, sostenida por la pobreza y suficiencia de la analogía, siempre exigida a la hora de decir nada sobre Dios - Deus semper maior - . Con todo, pese a la complejidad y limitación propias del discurso teológico, este no deja de ser una aportación única al logos universal. Por su carácter excesivo - pues trata de mirar las cosas desde Dios-, quizá sea la única racionalidad capaz de ensanchar los horizontes del imaginario presente, criticando los reduccionismos que pueda suponer - a nivel antropológico, sociológico o teológico-, y proponiendo «unos cielos nuevos y una tierra nueva» (2 Pe 3,13$)$, que habitar y hacia los que tender ${ }^{2}$.

Desde estas claves, focalizaremos nuestro acercamiento al imaginario contemporáneo desde los análisis de filósofo surcoreano Byung-Chul Han, recientemente nominado para los premios Princesa de Asturias de Ciencias Sociales 2017. Su perspectiva — como cualquier otra—, es parcial y acotada a su misma epistemología - filosófica y, por eso, inmanente-, pero no por ello deja de ser sugerente y remitir a algunos aspectos del imaginario contemporáneo; ese lugar compartido que se descubre como el fondo del escenario donde trascurre la vida, donde se sitúan los acontecimientos y las relaciones, donde encontramos una herencia de sentido que, "como "potencia unificadora", va más allá de nuestra razón» ${ }^{3}$.

\section{HaCIA UNA FENOMENOLOGÍA DEL «CANSANCIO ANTROPOLÓGICO»}

Las obras más editadas del filósofo apuntan hacia una concepción de lo humano como entidad agotada, manifestando el imaginario presente tras los fenómenos de la globalización, la comunicación, las redes sociales, etc., y que podemos considerar como una «antropología cansada». No porque la reflexión claudique, ni porque el fenómeno humano se agote, ni porque su propuesta antropológica sea el cansancio, sino porque los criterios y opciones que marcan el paso de los días, llevan —más allá de lo físico-, al cansancio vital; a la fractura del sujeto, de sus horizontes y de su contexto. Sin querer entrar en un análisis profundo de su reflexión, veamos algunos elementos de su descripción.

2 Estas dos tareas — crítica y propositiva-, son las que M. Seckler articula en las denominadas "Apologética adversativa» -Adversative Apologetik- $\mathrm{y}$ «Apologética transpositiva o referencial» -Transpositive (oder referentielle) Apologetik que, junto a la «Teoría de la Apología» - Theorie der Apologie_, despliegan la función ad extra de la «Teología apologética». Cf. M. SeCKLER, «Fundamentaltheologie: Aufgaben und Aufbau, Begriff und Namen», en W. Kern-H. J. Pottmeyer-M. Seckler, Eds., Handbuch der Fundamentaltheologie. 4. Francke Verlag 22000, 331-402, especialmente, 386-394.

3 A Gesché, El sentido, Sígueme, Salamanca 2004, 157. 


\subsection{Productividad}

En su primer ensayo traducido al castellano - La sociedad del cansancio-, B.-Ch. Han focaliza su reflexión en el imperativo categórico de la actualidad. Éste no se caracteriza por el «debes», sino por el «puedes». No es una sociedad de carácter disciplinario - moral—, sino una sociedad donde impera el rendimiento sin límites. "Lo que enferma no es el exceso de responsabilidad e iniciativa, sino el imperativo del rendimiento, como nuevo mandato de la sociedad de trabajo tardomoderna» ${ }^{4}$. Por ello, se ve como una cualidad el multitasking; esa capacidad para hacer muchas cosas a la vez. Cualidad que, más que desplegar el potencial humano, genera una regresión a la animalidad más primaria; en detrimento de la capacidad de concentración y de contemplación, propias del ser humano.

De manera semejante, la acción humana, aquella dotada de significado en la que el hombre se expresa, unifica y realiza, queda degradada convirtiéndole en mero animal laborans, hiperactivo e hiper-neurótico. Agotado en la mera productividad, desemboca en dos alternativas: el tedio de la cotidianeidad —el mero aburrimiento-, o en la búsqueda de experiencias que hiper-estimulen su productividad; bien por la vía del dopaje, bien por la vía de la novedad y extravagancia constante.

\subsection{Transparencia}

Otro factor descrito por B.-Ch. Han, en La sociedad de la transparencia, es su carácter unilateralmente positivo. Con la transparencia se cree conseguir la verdad exclusivamente en función del positum; de lo puesto delante como evidente, de lo constatado exclusivamente por los sentidos. Por este motivo, B.-Ch. Han considera la sociedad transparente como pornográfica y obscena; como aquella que rechaza toda demora, toda instancia que detenga el acceso a la verdad por la vía de la reflexión ${ }^{5}$. «La sociedad positiva se despide tanto de la dialéctica como de la hermenéutica» ${ }^{6}$. Lo que se muestra es lo verdadero y, ante ello, no se puede más que asentir positivamente —no hay más que ver las opciones que dan las redes sociales con los contenidos mostrados-. No hay opción para la negatividad, porque lo que se ve es lo verdadero. No ha misterio, porque el misterio no es evidente. Todo es luz, no hay contrastes. No hay interioridad, porque todo ya es mostrado ${ }^{7}$. Sin embargo, como recuerda el filósofo, "transparencia y verdad no son idénticas. Esta última es una negatividad en cuanto se pone e impone declarando todo lo falso. Más

4 B.-CH. Han, La sociedad del cansancio, Barcelona 2012, 29; Cf. ID., La agonía del Eros, Herder, Barcelona 2014, 19-30.

5 Cf. B.-Сh. Han, El aroma del tiempo. Un ensayo filosófico sobre el arte de demorarse, Herder, Barcelona 2015.

6 B.-- $\mathrm{CH}$. HAN, La sociedad de la transparencia, Herder, Barcelona 2013, 18.

7 Cf. B.-Сн. Han, Psicopolítica, Herder, Barcelona 2014, 20-26. 
información o una acumulación por sí sola no es ninguna verdad. Le falta dirección, a saber, el sentido»8.

\subsection{Exposición}

La sociedad de la transparencia implica una manera de existir que, para ser, debe ser expuesta. Algo solo tiene valor en cuanto es visto, pues, en cuanto expuesto, es aceptado. De ahí la proliferación de toda una gama de recursos para la exposición y la difusión, para gustar lo aceptadamente expuesto; tanto en la transformación de la imagen-filtros, editores-, como en la transformación del original - cirugía estética, tratamientos- Toda una serie de medios para saltar el peaje de la negatividad y, por tanto, extraviarse del camino de la verdad; ya no se puede decir, «esto que se ve, no es tal como se ve».

La exposición lleva también a la explotación y a la productividad, antes mencionadas. Entonces es cuando uno, o lo expuesto, se convierte en mercancía. Es el máximo nivel de despersonalización y deshumanización. Los llamados influencers - aquellos que marcan tendencias en el consumo, en la opinión, etc.- , se convierten, no solo en vehículos de una imagen explotada, sino en objetos mismos de producción. La cultura de la exposición se revela, entonces, como un Big Deal, donde todo es capitalizado y comercializado9.

\subsection{Acumulación}

Una última consideración sobre las tesis de Han nos lleva a En el enjambre. Queriendo referirse con esta metáfora al mundo digital y a la proliferación de la información; fenómeno que transciende lo meramente cognitivo. Hoy día, quien tiene la información, tiene el poder. Esta se acumula y se vende; con ella se especula y se manipula. El enjambre de datos, aunque adquiera la forma de - y contenga en sí- una masa de identidades, carece de alma, de espíritu. Cuando se entra en el enjambre, el ser humano se convierte en homo digitalis y transforma su modo de ser en el mundo: invade un espacio exponiéndose y reclamando atención, pero de manera anónima, porque no deja de ser «un alguien anónimo» ${ }^{10}$. Sin embargo, paradójicamente, esta hipersocialización virtual huye de la masificación física o de la agrupación colectiva. Hay agrupación, pero no hay pertenencia colectiva.

Otro aspecto de la acumulación es la atomización del acontecimiento. El almacenamiento de una gran cantidad de datos inconexos y autónomos, se configura como una nueva creencia: el "dataísmo» ${ }^{11}$, cuyo trasfondo es el nihilismo. La acumulación carece de sentido porque es una mera adición de datos y números, sin narratividad ni trasfondo. Tras ellos no hay nada y su conjunto tampoco es nada.

\footnotetext{
8 B-CH. HAN, La sociedad de la transparencia. o. c., 23.

9 Cf. B-Сh. Han, Psicopolítica, o. c., 98-100.

10 B.-CH. Han, En el enjambre, Herder, Barcelona 2014, 29.

11 Cf. B-Сн. Han, En el enjambre, o. c., 85-113. Aquí, 87.
} 
2. El AGOTADO IMAGINARIO CONTEMPORÁNEO Y SUS DIFICULTADES PARA LA TRANSMISIÓN DE LA FE

Este breve e incompleto acercamiento a las tesis de B.-Ch. Han, probablemente haya provocado alguna reflexión y quizá alguna vía de solución. Animo a leer sus obras para tener una nueva mirada sobre el contexto actual y las repercusiones que pueda tener. Sin duda, más allá de la descripción sobre los ritmos de vida o de las realidades del mundo de la comunicación, estos factores inciden en el imaginario contemporáneo y, desde él, en la cosmovisión - presente y futura-, en los procesos de construcción de la identidad, en los modos y criterios de relación, en la esfera axiológica, y, evidentemente, en ámbito simbólico y religioso.

\subsection{Resistencia y sumisión}

B.-Ch. Han, a pesar de no hacer ninguna propuesta en firme ante la realidad descrita, indica una serie de vías para salir o, por lo menos, no salir demasiado herido de este ecosistema en el que vivimos. La vía contemplativa, el arte de demorarse, la narratividad de los acontecimientos, la salvación por la belleza ${ }^{12}$, etc., parecen ser los remedios para que la "sociedad del cansancio» no fagocite a sus miembros. Con todo, según indica David Le Breton en su obra Desaparecer de sí - con descripciones convergentes a las de B.-Ch. Han-, la solución comúnmente adoptada es la «blancura» ${ }^{13}$. Por ella, el antropólogo francés entiende un estado de ausencia de sí más o menos prolongado. Responde al sentimiento de saturación y de hartura, desconectando al sujeto de su contexto ordinario - relaciones, tareas-, e incluso de sí mismo. En los momentos o estados de blancura, el individuo desconecta de su identidad y, o bien desaparece, o bien adopta una totalmente diversa, como si se tratase de una ficción. Solución parcial porque siempre supone volver a encontrarse, a enfrentarse y a padecer, el flujo de la vida que le agota y deshumaniza, sin más solución que la huida temporal. Aparentemente hay resistencia, pero realmente se vive sumiso a las coordenadas impuestas por la sociedad.

Ambas propuestas, según nuestro modo de entender, tienen un corto recorrido, puesto que no visitan en sus reflexiones la hondura de lo humano ni su complejidad, constitutivamente trascendente, religiosa e, incluso, teológica. Quizá convenga retomar aquello que H. Arendt dijo en La condición humana: «El interrogante sobre la naturaleza del hombre no es menos teológico que el referido a la naturaleza de Dios; ambos sólo cabe establecerlos en el marco de una respuesta divinamente revelada $»^{14}$.

12 Cf. B.-Сн. Han, La salvación de lo bello, Herder, Barcelona 2015, 105-110.

13 D. Le Breton, Desaparecer de sí. Una tentación contemporánea, Siruela, Madrid 2016, $15 \mathrm{ss}$

14 H. Arendt, La condición humana, Paidós Ibérica, Buenos Aires-Barcelona-México52009, 34 . 


\subsection{Dificultades para la trasmisión de la fe}

Pero la cuestión es que, si bien la respuesta, o el cuestionamiento de la realidad, puedan venir del marco de la revelación —así lo creemos nosotros-, no es menos cierto que, como dijo J. P. Gallagher, los perfiles de la secularización parecen haber mermado nuestra capacidad de acogida de la revelación ${ }^{15}$. El ex auditu de la fe (Rom 10,17) parece que no tiene cabida en la sociedad de la imagen. No solo por su cerrazón ante el extra nos de lo revelado, o su testimonio y del anuncio, sino por la incapacidad, intra nos, para escuchar el querer del corazón humano. Si esta resistencia sucede para la acogida de la fe, todo lo que ella implica —o pueda llevar a ella—, es marcadamente contracultural y, por eso, rechazado.

Así, la permanencia, fidelidad y firmeza, propias de la fe, generan no poco rechazo ante la hiper-estimulación, la aceleración y el diletantismo contemporáneos. La Verdad de la fe y sus verdades, son insoportables en una sociedad que huye de la negatividad. La no evidencia del término de la fe, se recibe como un imposible ante la dictadura de la transparencia del positum. La gratuidad de la fe se revela como sospechosa en la sociedad de la productividad y del negocio. El carácter histórico y narrativo de la fe, no encuentra espacio en la acumulación de datos sin sentido, ni destino.

Otros muchos aspectos podrían ser indicados. Todos, a fin de cuentas, nos llevarían a la cuestión del nihilismo. Ese «huésped inquietante» ${ }^{16}$ que reconfigura nuestro imaginario como algo exclusivamente inmanente y clausura toda apertura radical, toda relación comprometida, todo relato donador de sentido. En definitiva, toda oportunidad para reconfigurar la vida y sus imaginarios, desde el Dios revelado en la persona de Jesús por la fuerza del su Espíritu.

\section{3. ¿Qué tenemos que hacer?}

Es la pregunta que, no en pocas ocasiones, aparece en la Escritura cuando los oyentes de Jesús, o de la predicación apostólica, recibían la denuncia a su vida extraviada ${ }^{17}$. Es la pregunta que nosotros, como Iglesia, nos hacemos para llevar a término la misión encomendada.

Lejos de toda negociación, rendición o atrincheramiento cognoscitivos, como respuestas-tipo según P. L. Berger ${ }^{18}$, bien podemos adoptar aquella divisa con la que M. Blondel acompañaba la lectura de sus libros y de la realidad: «Por

15 Cf. J. P. Gallagher, El evangelio en la cultura actual. Un frescor que sorprende, Sal Terrae, Santander 2014, 41.

16 Cf. U. Galimberti, L'ospite inquietante. Il nichilismo e i giovani, Feltrinelli, Milano 2007.

17 Lc 3, 10. 12. 14; Jn 6, 28; Hch 2, 37.

18 Cf. P. L. Berger, Una gloria lejana. La búsqueda de la fe en época de incredulidad, Herder, Barcelona 1994. 
las cosas que se ven y no son, a las que no se ven y son ${ }^{19}$. Era el lema del $e x$ libris con el que sellaba cada uno de sus libros. Una formulación de inspiración paulina que revelaba su método filosófico y su comprensión de la realidad. Siguiendo su intuición, debemos preguntarnos ¿qué es aquello que se muestra en la realidad descrita? ¿A qué nos remite?

Como hemos indicado, yendo al trasfondo de las soluciones propuestas por B.-Ch. Han y descritas por D. Le Breton, estas pueden ser leídas como una manera de resistencia que, desde nuestra perspectiva, no aciertan con la solución y se tornan en formas de sumisión ante lo inmanente. Por ello, quizá sea necesario retomar aquello que genera la resistencia y el rechazo. No lo que lo provoca, sino, precisamente, lo que se rebela contra la productividad, la inmediatez, la transparencia, la acumulación sin sentido. En definitiva, contra la imposición de este imaginario que configura los días en una sucesión de momentos sin sentido. Retomar el origen del rechazo ante estos condicionamientos nos llevará a descubrir aquello que provoca la necesidad de contemplar, de encontrar narraciones que den sentido y destino, de indicar qué debe ser contemplado, como para activar la ascesis ante la inmediatez y, desde ello, trans-as-cender, en palabras de J. Wahl, los acontecimientos y a uno mismo ${ }^{20}$.

Lejos de todo ejercicio pelagiano de la voluntad y de toda terapéutica budista contra el dolor, partir del origen de este conjunto de reacciones y de necesidades impuestas ante la "sociedad del cansancio», es dejar que la huella de la alteridad radical que nos habita y constituye, nos lleve hacia su origen. El cual, a su vez, se revela como nuestro destino. En una palabra, nos lleve hacia Dios.

\section{Claves Para la transmisión de la Fe}

Sintéticamente, por la naturaleza de este ensayo, nos acercamos a dos posibles vías de solución o de salvación —rememorando la etimología de la misma palabra ${ }^{21}$ - . No sin antes recordar, que no es cuestión de otorgarnos a nosotros mismos «soluciones» o "salvaciones», puesto que se caería en la ingenuidad del Barón de Münchhausen o en la misma y agotada inmanencia. No se trata de eso, cuanto de educarnos. Sólo así podremos ser conducidos y acoger la solución — salvación — al enigma de la vida, mutuamente iluminado desde el misterio de la fe. Junto a la educación del deseo y de la esperanza — en las que nos vamos a detener-, bien podrían desarrollarse otros ámbitos que educar, como la mirada, la identidad, la relación, la palabra, el compromiso, la reflexión, etc.

19 "Per ea qua videntur et absunt, ad ea quae non videntur et sunt». M. BLondeL, Carnets intimes. II. (1894-1949), Cerf, Paris 1996, 193.

20 Trans-ascender es la formulación de J. Wahl para significar la ascensión religiosa desde la inmanencia, propuesto junto al concepto de trans-descendencia, con el que se indica el movimiento de Dios hacia el hombre. Cf. J. WAHL, Existence humaine et transcendance, La Baconniere, Neuchatel 1944, 37-40; G. Amengual, Deseo, memoria y experiencia. Itinerarios del hombre hacia Dios, Sígueme, Salamanca 2011, 45-84.

21 Cf. A. Gesché, El destino, Sígueme, Salamanca 22007, 32. 


\subsection{Educar el deseo}

Quizá un primer ámbito que educar sea el deseo. Aquel que moviliza la voluntad y su querer. Aquel que siempre queda irresuelto, por muchos logros y triunfos que se obtengan. Aquel que se revela como infinito en la finitud de nuestra existencia. Aquel que está más allá de las necesidades creadas por la sociedad de la transparencia, la exposición y la productividad ${ }^{22}$.

Educar el deseo supone un recorrido de ida y vuelta, que transita por la permanente inadecuación entre lo que pensamos, queremos y hacemos ${ }^{23}$. Desproporción que revela la insuficiencia de toda necesidad satisfecha y la inevitable presencia de lo infinito en nosotros, así como nuestra posible —y quizá necesaria- adhesión a él.

Educar el deseo, supone liberarse de toda necesidad inmediata y de toda realización que no suponga una satisfacción instantánea. Supone ordenar los afectos conforme a su querer infinito; es decir, conforme a lo absoluto y definitivo. El deseo, ordenado desde este principio, no solo estaría libre de toda limitación — por muchas que padezca-, sino que, incluso, sería capaz de amarlas, porque amaría lo infinito que está tras ellas y en ellas. Es cuestión de instalarse en otro nivel de realización que, sin desentenderse de la contingencia de la cotidianidad, no se deje absorber por sus condicionamientos, ni morder por las urgencias, ni atrapar por las últimas tendencias. Es una libertad de espíritu y de realización, precisamente, porque se está comprometido con lo definitivo que se rebela contra lo temporal y relativo; porque se ha puesto la libertad y su querer, en algo Otro, de quien, nada ni nadie, nos pueden privar; ni siquiera la propia existencia fracturada, puede causar la ruptura del vínculo infinito que nos une con el principio y fin de nuestro deseo; con Dios.

Vistas desde aquí las cosas, todo adquiriría su peso y su valor, siendo estos relativos. Todo adquiriría sentido universal, en la particular narratividad de la existencia. Todo quedaría invadido por el exceso y, no por ello despreciado. Todo sería indiferente conforme a lo único necesario, aunque todo tenga su irremplazable lugar para llegar a él.

\subsection{Educar la esperanza}

Como intuimos, directamente relacionado con la educación del deseo, está la educación de la esperanza. Virtud que se manifiesta como urgente y necesaria, ante la respuesta de la «blancura» y desconexión, que no trasformarían la realidad, ni impulsarían al hombre a encarnase en ella. Lejos de una asunción de los criterios de validez y de los ritmos de vida impuestos, la esperanza es

22 Cf. G. Amengual, o. c.; J. Lacroix, Le Désir et les désirs, PUF, Paris 1976.

23 Síntesis del método de la inmanencia formulado en, M. Blondel Lettre sur les exigences de la pensée contemporaine en matière d'apologétique, en ID., Euvres complètes. 18881913. La philosophie de l'action et la crise moderniste, T. II, PUF, Paris 1997, 128. 
esa resistencia interior frente a todo impedimento que limite la dignidad de la propia existencia y la consecución de su destino.

Como «hermana de la utopía», la esperanza se convierte en instancia crítica ante toda realización que la impida tener lugar. Bien sabemos que la utopía no tiene lugar —ou-topos-, pero tampoco nos es desconocido que la utopía es alimentada por gestos que, por su carácter profético y simbólico, anuncian y unen — symballein—, a una realidad futura y, a la vez, limitadamente presente. Así, la esperanza, contra toda crítica, no es el opio que adormece las conciencias, sino el reactivo que las moviliza hacia su realización plena. «Propone lo imposible [...] mientras que, como sabiduría muy de este mundo, solo ordena exigir lo posible $»^{24}$.

Por eso, la esperanza, lejos de la desconexión o la «blancura» antes mencionadas, es el vínculo que enlaza lo posible y lo imposible, lo utópico y lo presente. Abre los acontecimientos a una historia con sentido y con destino, rompiendo la simple acumulación de momentos atomizados, inconexos y planos. La esperanza puede atravesarlos con su temporalidad específica: el kairos. Comprendido como la visitación del tiempo divino por el que la eternidad se inserta en nuestro tiempo. Es el momento propicio, favorable, oportuno, el tiempo de la salvación aquí presente entre nosotros. "Nuestro 'ahora' es un tiempo que ya tiene un valor de eternidad y de destino ${ }^{25}$. Por eso el destino del hombre también se juega en este mundo. No como simple prolegómeno, sino como realización proléptica. La vida en nuestra tierra, en su cotidianeidad, cansada y transparente, es objeto de ese destino al que estamos llamados.

¿Seremos capaces de iniciar estas vías o delinear otras - a nivel teórico y práctico-, siendo radicalmente contraculturales? ¿Tendremos espacios para poder ofrecerlas y visibilizarlas? ¿Cuánto tiempo podrá seguir la humanidad transitando por estas sociedades que la deshumanizan? ¿No tendría la fe cristiana que «poner en valor» — como es acostumbrado decir ahora- estos fundamentos propios de lo humano, estas balizas, que indicasen el camino a seguir? Quienes compartimos la fe $i$ No tendremos la urgencia y la responsabilidad de vivir y ofrecer espacios dónde sean reales nuestras pretensiones, por otra parte, bien universales? Más preguntas que respuestas, para concluir nuestra reflexión. Al fin y al cabo, la resolución de la sociedad descrita, tendrá su término en el mismo lugar donde se originó: en la práctica de la vida. En su unidad, en su complejidad y en su concreción.

Universidad Pontificia Comillas

sgmourelo@comillas.edu

Santiago García Mourelo

[Artículo aprobado para publicación en enero de 2018]

24 A. Gesché, El hombre, Sígueme, Salamanca 2002, 54.

25 A. Gesché, El destino, o. c., 112; Cf. ID. El hombre, o. c., 113. 